\title{
New modalities of treatment for hepatocellular carcinoma
}

\author{
Arman Karimi Behnagh, ${ }^{a}$ Negar Rezaei, b,c Mohadeseh Jahannia, Zeynab Noorimotlagh, ${ }^{a}$ Ali Kabir ${ }^{\mathrm{d}}$
}

\author{
aStudent Research Committee, Faculty of Medicine Branch, Iran University of Medical Sciences, Tehran, Iran. \\ bDepartment of Epidemiology, School of Public Health, Iran University of Medical Sciences, Tehran, Iran. \\ cNon-Communicable Diseases Research Center, Endocrinology and Metabolism Population Sciences Institute, Tehran University of Medical Sciences, Tehran, Iran. \\ dMinimally Invasive Surgery Research Center; Iran University of Medical Sciences, Tehran, Iran. \\ Correspondence to Ali Kabir (email: aikabir@yahoo.com). \\ (Submitted: 12 May 2017 - Revised version received: 29 May 2017 - Accepted: 10 June 2017 - Published online: 26 September 2017)
}

\begin{abstract}
Hepatocellular carcinoma (HCC) is the second most common cause of death from cancer worldwide. Managing HCC is difficult. However, there are many treatment options available such as liver transplantation, radiotherapy, different ablative techniques, surgery, trans-arterial chemoembolization (TACE) and systemic therapy. These treatments did not show the promising responses and the recurrence rate is still high. On the other hand, there are some new treatments such as immunotherapy, gene therapy, combination of different therapies, Chinese traditional therapies and new targeted therapies. The aim of this study is to review both the recent changes in the common therapies and newly developed therapies of HCC.

Keywords carcinoma, hepatocellular, treatment, combined modality therapy
\end{abstract}

\section{Introduction}

Hepatocellular carcinoma (HCC) is the second most common cause of death from cancer worldwide. It is the fifth most common cancer in men and the ninth in women. In addition, the incidence rate is almost equal to the mortality rate. ${ }^{1}$ Many risk factors are known for HCC, such as age, gender, alcohol, $\mathrm{HCV}, \mathrm{HBV}$, and non-viral chronic liver disease. Moreover, currently among these risk factors $\mathrm{HBV}$ and $\mathrm{HCV}$ are the most important ones. ${ }^{2}$ Managing HCC is difficult. However, there are many treatment options available such as liver transplantation, radiotherapy, different ablative techniques, surgery, trans-arterial chemoembolization (TACE) and systemic therapy. ${ }^{3}$ These treatments did not show the promising responses and the recurrence rate is still high. ${ }^{4}$ On the other hand, there are some new treatments such as immunotherapy, ${ }^{5}$ gene therapy, ${ }^{6}$ combination of different therapies, Chinese traditional therapies and new targeted therapies. ${ }^{7}$ The aim of this study is to review both the recent changes in the common therapies and newly developed therapies of HCC.

\section{Methods and Materials}

A focused literature review was performed in Medline, Embase and Cochrane Library to find the recent studies on the treatment of HCC. We limited our search to recent 5 years, although we bring a few numbers of older studies while we do forward-backward citation. In addition, we only evaluate the studies which were mainly about the human species and were published in English. For including studies in our review, we performed a double phase assessment. In the first phase, we considered only titles and abstract and in the second we assessed the full text to find out the relevance of the studies to our work. Based on this explanation, we included 4622 references. After removing duplicates, 3788 references were assessed in the first phase. Then, 1665 studies were excluded. As of the remaining studies, 387 of them were removed in the second phase. Among 1349 remaining ones, 173 studies were selected to include in this study. An adapted PRISMA flow diagram shows the process (Fig. 1). Our exclusion criteria for both phases were: complications, biomarkers, prediction and progression factors, case reports, imaging, preclinical studies (in vitro and animal studies), cost and economy, risk factor and some other nonrelated subjects to the therapy of HCC.

Below, we briefly explain different therapies of the HCC considering new changes and recent modalities and treatment options.

\section{Chemotherapy}

One of the chemotherapy multi resistance tumours is HCC. It has a very low survival and despite the huge amount of scientific work in this matter, it appears that systemic chemotherapy is unsuccessful in HCC treatment. ${ }^{8}$ Doxorubicin is the chemotherapy of choice from past, but the effect of this drug on survival rate was equal or inferior, comparing with other chemotherapy drugs in several clinical trials. ${ }^{9,10}$ There were also a systematic review of 800 patients and 13 trials applying doxorubicin chemotherapy compare to other chemotherapies. The results showed chemotherapy in advanced HCC have poor effects. Doxorubicin monotherapy is not inferior to comparing with combination multiple drug chemotherapy or biological agents. ${ }^{10}$ Using Platinum-based chemotherapy with Oxaliplatin like PIAF schedule $($ Cisplatin + Interferon + Doxorubicin $+5-\mathrm{FU})$, minimizing toxicity and is better to be used for older patients. Though the overall survival (OS) is not significantly different from doxorubicin. ${ }^{10}$ Nonetheless, there are not randomized trials of Platinum agents in HCC systemic treatment, FOLFOX have uncertain benefits comparing with Doxorubicin. ${ }^{11}$ Sorafenib therapy is an alternative palliative therapy that will be discussed later in this article.

\section{TACE}

TACE is a standard palliative, down staging therapy in patients with progressive inoperable HCC since 1970. It has been used in intermediate HCC that we have few choices of treatment. ${ }^{12,13}$ The main concept of chemoembolization is to emboli the hepatic artery which is the main hepatic tumour vessel. This procedure may cause tumour death without affecting normal tissue. ${ }^{14}$ In addition, a chemotherapy agent delivered to hepatic vessel. There are not a standard protocol for the choice of chemotherapy 
drug or dosage, or rate of usage. ${ }^{15}$ Anthracyclines (daunorubicin, doxorubicin, epirubicin), platinum-based agents (cisplatin, lobaplatin, miriplatin), mitomycinC, and 5-fluorouracil is the chemotherapy drugs used in TACE. There are not noteworthy superiority reported on using specific chemotherapy agent in TACE. ${ }^{13}$ A systematic review of 15 studies comparing TACE with conservative management had reported that the patients with portal vein branch invasion and well liver function may achieve optimal advantage from treatment with TACE ${ }^{16}$ Another systematic review on five randomized trials compared TACE with and without chemotherapy treatment. The results revealed no superiority of using chemotherapy with chemoembolization and the adverse effect of treatment is even higher in the TACE group compared to TAE. ${ }^{17}$ There are also alternative choices like balloon-occluded transarterial chemoembolization (B-TACE) using miriplatin (a lipo-philic anticancer drug) and gelatin particles. A significant higher local node treatment in B-TACE with the miriplatin group in comparison with routine TACE was reported in a non-randomized trial. ${ }^{18}$ In addition, no significant difference was reported, between TACE-miriplatin plus epirubicin and TACE-miriplatin group in the efficacy of therapeutic and adverse effects. ${ }^{19}$ Although lack of a randomized controlled trial (RCT) is noticeable in this issue.

\section{DEB-TACE}

Doxorubicin-eluting beads (DEBs) is an embolization device with TACE treatment. It is used in hypervascular tumours and emboli vessels with simultaneous administration of tumour located, controlled, sustain released dosage of chemotherapy which is mainly doxorubicin. These beads consist of vinyl alcohol and sulfonic acid groups with chemotherapy agents in different sizes. ${ }^{20}$ This method is widely available since 2006, and the treatment effects are assumed to be superior compared to TACE. ${ }^{21}$ There are two systematic reviews on our search which compare the DEB-TACE with TACE. These studies, approximately include same studies with very inconsistent results. In addition, there are just few RCTs in this issue. These studies are not reporting a significant difference on survival rate. ${ }^{22,23}$ Other studies are non-randomized trials or retrospective researches assessing the registries or have a low sample size or could not evaluate survival rate, which makes the interpretation and decision of the reported results imprecise. ${ }^{24,25}$ However, a recent non-randomized controlled trial reported non-significant difference in survival rate between TACE and DEB-TACE in non-operable HCC patients. As the number of TACE treatment needed is higher than DEB-TACE with the same survival rate, DEB-TACE is more preferred by both clinicians and patients. ${ }^{26} \mathrm{~A}$ meta-analysis in 2013 with seven studies (693 participants) reported no significant difference between the two procedures in hard outcomes. It has been also mentioned the need of running more RCT on this issue for better decisions, ${ }^{27}$ while a meta-analysis in 2014 included seven studies (700 participants). It has reported a better tumour response with DEB-TACE. Although the survival rate was reported to not change significantly after 3 years and adverse side effects are also similarities between the two procedures. ${ }^{21}$

\section{Gelatin Sponge Particle TACE}

Gelatin sponge is an embolic agent generally used for embolization therapies of various diseases over 30 years. The size of embolic agent has direct influence on embolic effects. Gelatin sponge particles are around $1-1.5 \times 1-1.5 \times 2 \mathrm{~mm}$. It has been made from either Spongel or Gelfoam sheets. ${ }^{28}$ There are three embolization effect classifications named "short term", "medium term" and "long term". Gelatin sponge micro particles (GSMs) have medium effect. ${ }^{29}$ Using the embolization component in TACE procedure increases the rate of necrosis of the main tumour and Gelatine sponge particles is used frequently in embolization procedures. ${ }^{30}$ Gelatin sponge microparticles in a rabbit liver tumour were assessed in 2014. The results suggested the usage of GSMs-TACE comparing to c-TACE group and hepatic arterial infusion (HAI) group have higher concentration of chemotherapy drug with slow drug release. ${ }^{31}$ Human research also showed good tolerance on GSMs and the OS rate was $100 \%$ in six months and $87.5 \%$, in one year. ${ }^{32}$ Other parallel studies confirmed the safety and effectiveness of gelatin sponge particle TACE for treatment of the Barcelona-Clinic Liver Cancer (BCLC) stage B HCC patients. ${ }^{32}$

\section{Hepatic Resection vs. TACE}

Up to now, the curative choices of HCC are liver transplant, hepatic resection and radiofrequency ablation. Liver transplant appears to be gold standard treatment, but it is restricted because of the low number of donors. Hepatic resection is a better choice than radiofrequency ablation for the OS. In addition, for palliative treatment options we have TACE and sorafenib. TACE is generally used for HCC patients further than the BCLC stage A classification. ${ }^{33}$ Two systematic reviews and meta-analysis compared the hepatic resection with TACE in OS of patients further than the BCLC stage A classification. The results of both are parallel and reported a significant overall one- and three-year better survival in hepatic resection group. ${ }^{33,34}$ Although, the lack of RCT in this issue was mentioned in both systematic reviews.

\section{Cytokine Induced Killer Cell}

Recently, immunotherapy is a new modality in cancer treatment. Cytokine-induced killer (CIK) cells are effective adoptive cell-based immunotherapy treatment. The concept of this treatment is to stimulate body immune response against tumour cells. So, the adverse side effects of chemotherapy and surgical procedures are minimized. CIK cells are natural killer like $\mathrm{T}$ cells and express both the $\mathrm{T}$ cell marker $\mathrm{CD} 3$ and the NK-cell marker CD56. The idea of applying CIK cells in cancer therapy was first reported by Schmidt-Wolf et al in 1991 on an animal model. In 2010, Stanford Medical University established an international registry on CIK cells (IRCC) for better application of this treatment based on clinical evidence ${ }^{35}$ particularly, researchers from china performed RCTs on combination CIK with TACE for HCC treatment. It is reported that the combination therapy improves quality of life and prevent cancer recurrence. ${ }^{36}$ There is a systematic review comparing CIK-TACE with TACE alone in the HCC cancer treatment. Two RCTs and four non-RCT studies were included with 428 patients. The OS and progression-free survival (PFS) rates are better in the group treated with CIK-TACE. ${ }^{35}$

\section{Liver Transplantation}

In the category of curative treatments for HCC and cirrhosis, liver transplant is a choice. In this procedure, liver tumour and underling cirrhosis and possible risk of recurrence after resecting tumour will be removed. HCC patients will be 
candidates for liver transplant based on tumour size and nodule numbers. Milan criteria are particularly used for choosing HCC patients for liver transplant (a solitary tumour nodule up to $5 \mathrm{~cm}$ or three nodules less than $3 \mathrm{~cm}$ ). Because of the limited number of liver grafts, HCC patients must be selected. Vascular invasion, high alpha fetoprotein concentration, aggressive biology of tumour, multifocal large size tumour and having other comorbidities are the other exclusion criteria for this treatment. ${ }^{37-40}$ Fei Teng et al had described one-, three- and five-year survival rate of HCC patients after liver transplant: $78.9 \%, 53.2 \%$ and $46.4 \%$, respectively. ${ }^{41}$ However, the lethal nature of HCC in addition to low source of liver graft makes it difficult to run RCTs and the lack of evidence is tangible in this concern. There are different criteria available for selecting HCC patients for liver transplant apart from Milan criteria. The most popular one is University of California, San Francisco (UCSF). No significant difference was reported between applying these two criteria. Other criteria are the United Network for Organ Sharing (UNOS), Tokyo, Kyoto, Kyushu, Hangzhou and Up-to-seven. The detail on these criteria are available elsewhere. ${ }^{10,42}$

Down staging of HCC patient's candidate for liver transplant is unavoidable because of the high dropout rate for the duration of waiting for liver transplant. The main interventions for down staging are TACE, percutaneous ethanol injection (PEI), and radiofrequency ablation (RFA) and Sorafenib therapy in addition to TACE or DEB-TACE. However the lack of evidence in this area is obvious. ${ }^{42}$ However, current guidelines do not recommend a liver transplant for patients outside Milan criteria. ${ }^{43}$

\section{Salvage Liver Transplantation (SLT)}

To minimize the waiting list dropout rate, alternative treatments are used in this period, such as local therapies and surgery. It has been proposed for patients with small HCC and preserved liver function. The efficacy of salvage transplantation that is primary resection before transplantation is assessed by Poon RT et al in 2002. Salvage transplantation reduces recurrence or worsening of liver function in waiting time for liver transplant. ${ }^{45}$ The positive point of surgery specially laparoscopic surgery is the curative concentrating of resection, pathological analysis of tumour for vascular invasion, tumour differentiation, number of nodules affected and improving quality of life. The negative point of laparotomy is adhesion in the surgical site which makes next liver transplantation operation difficult. However, laparoscopic or robotic approaches result in lower adhesions in surgical site. Although liver function and size of tumour of patients do not let clinicians to use this approach in all patients. ${ }^{46}$ A systematic review with 1508 patients was conducted in 2013 on short and long term outcomes of SLT. Although the short outcomes like duration of operation is significantly higher in SLT than primary liver transplant, the OS rate after 1,3 and five years were not different. ${ }^{47}$

\section{Surgical resection}

Liver resection surgery is performed for nearly six decades. ${ }^{47}$ Surgical liver resection is a curative resection of the entire tumour in microscopic level with free of tumour cutting surface. Surgical resection is the treatment of choice in noncirrhosis HCC in early stages. The frequency of non-cirrhosis HCC in Asia is about 8 times higher than western countries. In other HCC patients' surgical resection may cause liver failure. So, these patients must be selected carefully for surgical treatment. ${ }^{48}$ Prognostic factors for liver resection are tumour size, high level of alpha fetoprotein, micro and macro vascular invasion, and underlying liver disease such as cirrhosis. ${ }^{49}$

There are two types of resection; anatomical resection, which is wide liver resection beyond the borders of tumour and non-anatomical resection which is used in hepatic dysfunction and remains the most possible liver residue. There are some controversies reported on the type of resection. Some studies suggested survival benefits from anatomic resection, ${ }^{50}$ while the others reported no significant benefit. ${ }^{49}$ A systematic review suggested anatomic resection of liver approves survival and diminish recurrence comparing to non-anatomical but the studies included in this meta-analysis are not randomized trials. ${ }^{51}$ Liu $\mathrm{PH}$ in 2014 showed surgical resection with TACE in HCC patients beyond Milan Criteria. They had reported a noteworthy improved long term survival with surgical resection..$^{52}$

\section{LAPAROSCOPY}

The first laparoscopic liver surgery was performed four decades after open surgical liver resection. Currently, with more technical improvement in laparoscopic surgery, more malignant liver tumour resection is carried out with this procedure. ${ }^{53}$ There are few observational studies and a systematic review that compare open surgery and laparoscopic short-term and longterm outcomes on HCC and there are not noticeable differences between two surgical methods. ${ }^{54}$ The systematic review was conducted in 2012 and included 10 observational studies. The overall complication rate was lower in the laparoscopic group. The recurrence rate of HCC, 5-year survival, and 3-year survival was not significantly changed between two procedures. ${ }^{47}$

\section{Radiotherapy}

The role of radiotherapy (RT) is limited in patients with HCC due to low tolerance of normal liver tissue to radiation. However, new techniques in image guidance, breathing motion reduction strategies and appropriate dosimetry have been introduced for better local control and decreasing liver toxicity.

\section{Radioembolization}

Radioembolization (RE) delivers a high dose radiation through hepatic artery. Small microspheres loaded Yttrium-90, a B-emitter isotope is used in the case of RE. Two common 90Y devices are Thera-Sphere (BTG International, London, United Kingdom) which is a glass microsphere, and SIRSphere (SirtexMedical, Sydney, Australia) which is a resin microsphere. According to the literature, both microspheres have similar outcomes. ${ }^{55}$ Radiation segmentectomy and boosted radioembolization are considered two novelties in the field of RE.

\section{Radiation Segmentectomy}

The combination of microcatheter technology and the localized radiation emission properties of $90 \mathrm{Y}$ microspheres introduce a novel treatment called radiation segmentectomy. Since ablation and resection are not suitable for the lesion located near critical structure, radiation segmentectomy is an appropriate way to overcome this drawback. ${ }^{56}$ Michel et al conducted a follow up, multicenter study to assess the efficacy of radiation segmentectomy. Radiation segmentectomy was defined as $90 \mathrm{Y}$ microsphere infusion limited to $2 \geq$ couinaud 
segments. Dosing was achieved by infusing a calculated lobar dose into a segmental tumour-feeding vessel. Therefore, segmental doses are higher than lobar doses by the ratio of lobar/ segmental volumes. The results show, complete response (CR) in $47 \%$, and partial response (PR) in $39 \%$ of patients. ${ }^{57}$ A retrospective follow up study showed a CR of $95 \%$ of patients who received radiation segmentectomy. ${ }^{58}$

\section{Boosted Radioembolization}

Boosted radioembolization is a novel concept for HCC. It is a personalized therapy in which the priority is given to tumour dosimetry rather than liver dosimetry. In this method, a predictive dosimetry model, based on technetium-99m microaggregated albumin (MAA), single-photon emission computed tomography/computed tomography (SPECT/CT), is utilized to identify tumours that need boosted microsphere dosing for better response rate. ${ }^{59,60}$ In another retrospective cohort study, Garin et al showed that boosted radioembolization based on MAA SPECT/CT caused prolonged OS for HCC portal vein thrombosis (PVT) patients, without increasing liver toxicity. ${ }^{61}$

\section{Intensified modulated radiotherapy (IMRT)}

IMRT is an advanced three-dimensional conformal radiotherapy (3D-CRT) that allows greater control of dose distribution. Since, it can change the intensity of individual rays within each beam, it can cover the treatment volume to concave tumour shape. ${ }^{62}$ Helical tomotherapy (HT) and volumetric-modulated arc therapy (VMRT) are two advanced forms of IMRT.

\section{HT}

It is a highly advanced radiotherapy, in which a gantry 6-MV linear accelerator is rotated continuously through $360^{\circ}$ around the patient using tens of thousands of narrow beams. It integrates both IMRT and image guided radiotherapy (IGRT). IGRT system of HT is a daily mega-voltage computed tomography image guidance. ${ }^{63}$ Three cohort studies showed a survival benefit and efficacy in utilizing HT for HCC patients. ${ }^{64-66}$ In a recent retrospective comparative study of 118 HCC patients, conducted in 2016, median survival in patients treated with HT was significantly more than with 3D-CRT. ${ }^{67}$

\section{VMRT}

It is an advanced form of IMRT that unlike fixed-field radiation methods treat the tumour from all angles by rotating the beam around the patient. Rapid Arc TM (Varian Medical System, Palo Alto, CA) is a variation of VMRT. ${ }^{68}$ In radiotherapy of HCC patients, targeted volume is greatly affected by respiratory motion. Active breathing coordinator $(\mathrm{ABC})$ is a solution for gaining a better target volume. In order to determine the feasibility of rapid arc (RA) in association with $\mathrm{ABC}$, Gong et al conducted a study of 12 HCC patients. 3D-CRT, IMRT and RA plans were designed and $A B C$ was used for better assessment of target volume. The report resulted in better dose delivery and an accurate target volume besides shortening treatment time for RA. ${ }^{69} 4 \mathrm{D}$-CT is another solution to achieve better target coverage. $4 \mathrm{D}-\mathrm{CT}$ scanning synchronizes CT image with respiratory cycle and is able to predict tumour movement. Another study involved 10 patients showed RA with $4 \mathrm{D}-\mathrm{CT}$ or $3 \mathrm{D}-\mathrm{CT}$ associated with $\mathrm{ABC}$ can effectively deliver accurate target volume compared with 3D-CT with free breathing. ${ }^{70}$

\section{Stereotactic Body Radiotherapy (SBRT)}

When ablation or TACE fails, SBRT can be considered as an alternative therapy. SBRT delivers high radiation to focal HCC and decreases radiation induced liver toxicity by sparing other tissues. ${ }^{71}$ SBRT by Cyberknife ${ }^{\circledast}$ is a new technology for treatment of liver lesions that delivers 100 to 200 photon beams of $6 \mathrm{MV}^{72}$ For appropriate detection it requires gold fiducial markers in the periphery of tumour. A recent study, evaluated the possibility of implantation of gold fiducial markers and the imaging technique it requires. The important role of radiologist in implantation and applying sonographic guidance were concluded. ${ }^{73}$

\section{Helical Intensity-Modulated Radiotherapy-based Stereotactic body Radiotherapy}

HT is an alternative for delivering SBRT, in a recent paper published in 2016, the phase I trial was conducted by Jun et al. to evaluate the feasibility and toxicity of helical intensitymodulated radiotherapy (HIMRT) based stereotactic body radiotherapy (SBRT) in eighteen HCC patients. At a median follow up of 28 months for living patients, an OS rate of $69.3 \%$ and a well-tolerated toxicity was concluded. ${ }^{74}$

\section{Differential Hepatic Avoidance RT (DHART)}

In HCC patients with a high degree in the liver function heterogeneity as for cirrhosis patients, conventional RT methods cannot spare radiation to functional liver regions and it may lead to radiation induced liver disease (RILD) to overcome this drawback. Stephen et al. introduced a new modality for RT that is called differential hepatic avoidance RT (DHART). in this technique SC SPECT (Sulphur colloid Single photon emission tomography) images were used to spare region of functional liver through the use of dose painting techniques in proton pencil beam scanning (PBS) and photon volumetrically modulated arc therapy (VMAT) RT. This initial study indicated that DHART is achievable with either photon VMAT or proton PBS therapy in HCC patients. ${ }^{75}$

\section{Varian Trilogy $^{\mathrm{Tm}}$}

Varian Trilogy ${ }^{\mathrm{Tm}}$ is an RT delivery system that deliver a highly conformal radiation beam to a mobile target. It utilizes realtime Position Management ${ }^{\mathrm{Tm}}$ (RPM) for respiratory control and On-Board Imager (OBI) for image guidance. ${ }^{76} \mathrm{~A}$ prospective cohort study showed an excellent treatment outcome with minimal toxicity for this RT delivery system. ${ }^{77}$

\section{Ablation}

Ablative therapy is considered a treatment with high safety profile and local control. Radiofrequency ablation (RFA), microwave ablation (MW), laser induced tumour therapy (LITT) - all parts of thermal ablation- ethanol or acetic acid injection - as part of chemical ablation- cryoablation, brachytherapy, irreversible electro-poration (IRE), and high intensity focused ultrasound (HIFU) are all considered as ablative therapies. Here we discussed technical advances in utilizing RFA, MWA, brachytherapy and HIFU with a major focus on RFA.

\section{RFA}

Poor visualization is one of the complications of ultrasound (US)-guide RFA. Contrast-enhanced ultrasound (CEUS), contrast-enhanced computed tomography (CECT), and magnetic resonance imaging (MRI) are alternatives for the guidance of 
RFA. However, the short durations of the different vascular phases, absence of real-time imaging guidance and increased radiation exposure are the disadvantages of using these imaging techniques. ${ }^{78,79}$ To overcome these problems a method called "fusion imaging' or "real time virtual sonography", that synchronizes real-time US and CT or MRI, is introduced. ${ }^{80}$ Two cohort studies showed an excellent technical success rate, safety and effectiveness for RFA using fusion imaging. ${ }^{81,82}$

Reduced energy diffusion is a complication observed in RFA using conventional electrodes. Utilizing internally cold (IC) electrodes and saline-enhanced RFA are two techniques to overcome this drawback. However, these two techniques have their own problems, including the limitation of overheating and the risk of heating and ablation of non-tumour containing area respectively. ${ }^{83,84}$ Internally cooled wet (ICW) electrodes that have the ability of both techniques (IC electrode and salineenhanced RFA) are developed as a solution to compensate the limitations of these techniques. In a study, utilizing modified ICW electrode showed the safety and effectiveness of the technique and a successful local control. ${ }^{85}$ In a retrospective comparative study, including 165 patients, mean ablation volume was significantly greater and local tumour progression was significantly lower in patients treated with ICW electrodes compared with patients treated with IC electrodes. ${ }^{86}$

Conventional monopolar RFA devices have several problems including; systemic symptoms because of exposure to a wide area of the body, long ablation time and causing burns. In contrast to a monopolar device in which the electrical current flows between the electrodes and the grounding pad, in a bipolar device the current flows between two electrodes. Besides compensation for monopolar device complications, the bipolar device is more sufficient and makes a large thermocoagulation volume in a single ablation procedure. A multicenter open-label trial confirmed the efficacy and safety of The CelonPOWER System, which is a bipolar RFA device. ${ }^{87}$

Incomplete peripheral ablation of the tumour is another drawback of utilizing monopolar device; ${ }^{88}$ while, multipolar technique provides a probe inserted outside the parameters of target lesion (no touch technique) and allows ablation of the tumours from margin to center. This causes complete margin ablation. ${ }^{89}$ The pathological examination of 59 nodules in a retrospective study indicates an improvement in the rate of complete necrosis in no-touch multipolar radiofrequency ablation compared with monopolar technique. ${ }^{90}$

Placement of sodium hyaluronate solution onto the liver surface can be used as a procedure for RF ablation of HCCs located on the liver surface. It causes separating of liver from other organs during the procedure and decreases the damage to adjacent organs. A phase one study was conducted to assess the safety of intraperitoneal injection of the sodium hyaluronate solution. Complete ablation and observation of tumour recurrence in one of 28 patients indicated the safety and efficacy of the technique. ${ }^{91}$

\section{Microwave Ablation (MWA)}

MWA is a locoregional therapy that can be conducted with the guidance of US, CT or MRI. In a follow-up study, MWA was performed by using a real-time virtual navigation system. The technique effectiveness was $94.44 \% .{ }^{92}$ Low power output and small-diameter ablation is one of the complications of MWA..$^{93}$ Water or gas antenna cooling has introduced a solution for making higher power microwave system.
A retrospective cohort study reported that after utilizing a gas-cold system for MWA, overall primary technique effectiveness rate and OS rate were 91.6 and $76 \%$, respectively. The results showed the safety and efficacy of the technique. ${ }^{44}$ Risk of tumour seeding is considered for subcapsular tumours achieving thermal ablation. ${ }^{56,95}$ In order to reduce the probable risk of tumour seeding and local progression after thermal ablation for subcapsular HCC, a technique called NO-touch wedge ablation, was described by Premal et al. The technique involved probe placement at multiple oblique sites tangential and adjacent to the tumour, to create a sufficient ablation zone that is inclusive of the subcapsular tumour and the required peritumoural margins. After complete ablation of eight tumours, at an average imaging follow-up of 244 days, one case of local recurrence was observed. ${ }^{96}$ One of the limitations for US guided thermal ablation is suboptimal conspicuity of some subcapsular tumours or tumours located in hepatic dome, that may lead to causing damage to adjacent tissues. ${ }^{97,98}$ Artificial ascites and plural effusion introduced a solution for this drawback..$^{99}$ In a case-control study that the efficacy of MWA with artificial pleural effusion was evaluated. The analysis showed no statistical differences between case and control groups in the primary technique effectiveness and local tumour progression rates. ${ }^{100}$

\section{Brachytherapy}

Brachytherapy is an ablative therapy that utilizes interstitial implantation of radioactive seeds and delivers high dose radiation in the target area. Two types of radioactive seeds are applied, one of them is high energy gamma emitter (e.g., cobalt-60 and radium-226) and the other is low energy chemicals (e.g., iodine-125 and palladium-103). Because of the high energy irradiation of the first type, low energy seeds became more common in the past decades. ${ }^{101}$ CT-guided high-doserate brachytherapy (CT-HDRBT) is a new modality in ablative technique that uses iridium-192 seed, inserted through catheters with CT guidance. ${ }^{102}$ Two retrospective cohort study conducted by Collettini et al. evaluated the clinical outcome of CT-HDRBT in HCC patients and showed the effectiveness of this therapy in local tumour control of lesions unsuitable for resection or thermal ablation. ${ }^{103,104}$

\section{HIFU}

HIFU is a new ablative therapy in which a unique frequency of US wave of 0.8 to $3.5 \mathrm{MHZ}$ is used and can be focused at a distance from therapeutic transducer. The high focused energy is able to induce necrosis by increasing tissue temperature. ${ }^{105}$ Poor visualization of HCCs during HIFU treatment is an obstacle. Hiroyuki et al. reported a study of HIFU ablation assisted using color Doppler for the treatment of HCC. The usefulness of this method was concluded from the study. ${ }^{106}$ In another study conducted by Michele et al. magnetic resonance-guided focused ultrasound (MRgFUS) was assessed as a treatment for solid tumour in abdomen. The study resulted in the safety and feasibility of the technique. ${ }^{107}$

\section{Chinese Herbal Medicine}

Chinese herbal medicine is a type of traditional medicine used in cancer therapy for a long time ago. ${ }^{108}$ In the case of HCC, studies evaluated the mechanism of action of this medicine and also this therapy has been used in vitro, in vivo, and also in recent clinical trials. 


\section{Ruanjianhugan}

Oral Ruanjianhugan (RJH) tablets which were made up of ten medicinal materials are kind of Chinese herbal medicine used in a 22-year followed up clinical trial study. Results indicated that long-term intake of RJH increases OS in small HCC after resection. Also, it has preventive effects on small HCC recurrence. ${ }^{2,102,109,110}$

\section{Systemic Therapy}

\section{Antiangiogenesis Agents}

Tyrosine Kinase Inhibitors: Sorafenib. In the Chinese subset of GIDEON study in 2015, 338 patients were followed prospectively to assess the efficacy and safety of SORAFENIB. Median OS of Child-Pugh A patients were longer than Child-Pugh $B$ patients. Adverse effects (AE) comparison showed serious AEs $(25.0 \%$ vs. $23.0 \%)$ in Child-Pugh B patients. In overall, this study indicated that Child-Pugh B patients would be safely healed with sorafenib. ${ }^{111}$

Adjuvant sorafenib. Currently, sorafenib has been used as an adjuvant therapy after curative resection in BCLC-stage three patients. It has been indicated that adjuvant sorafenib was safe and well tolerated. OS and DFS had increased significantly in this study. ${ }^{113}$

\section{Sorafenib Combination}

\section{a. Sorafenib Plus Cytotoxic Chemotherapy Agents}

Doxorubicin: results of a phase II study indicated that median OS, PFS and time to progression (TTP) favored sorafenib. ${ }^{114}$ GEMOX (gemcitabine plus oxaliplatin): a randomized phase II trial showed no significant difference of the OS. ${ }^{115}$

Oxaliplatin: results of a phase II trial indicated that there is no considerable difference of OS and TTP between two groups. ${ }^{116}$

\section{b. Sorafenib Plus EGFR Inhibitors}

Erlotinib: no survival benefit favored this combination in a phase III trial. ${ }^{117}$

\section{c. Sorafenib Plus mTOR Inhibitors}

Everolimus: this combination failed to show significant advantages rather placebo in a phase III clinical trial on 546 patients. ${ }^{118}$

Temsirolimus: different phase I-II trials resulted in no favorable benefits of this combination. ${ }^{119-121}$

\section{d. Sorafenib plus MEK inhibitors}

Refametinib: results of first line study revealed good efficacy of this combination. Disease control rate (DCR) and overall response rate (ORR) were $43 \%$ and $5 \%$ respectively. ${ }^{122}$

Regorafenib. Regorafenib is a multi-kinase inhibitor which inhibits kinases in angiogenesis and oncogenesis. It has been tried as a second line therapy after sorafenib in phase I and II clinical trials. The ORR and the DCR of regorafenib were $3 \%$ and $72 \%$ respectively. Drug-related adverse effects consisted of hand-foot skin reaction, diarrhea, fatigue, hypothyroidism, anorexia, hypertension, nausea and voice changes. Median OS was 13.8 months. Thoroughly, regorafenib was well tolerated and has antitumour activity on HCC. ${ }^{123}$

Brivanib. Another TKI is brivanib which is a dual TKI receptor of VEGFR (VEGF receptor) and fibroblast growth factor receptor (FGFR). ${ }^{10,124}$ BRISK-FL trial of 1150 patients was performed to compare brivanib and sorafenib. Results of this trial favored none of them. OS, TTP, ORR, DCR was the same. Somehow, brivanib showed more toxicity than sorafenib. BRISK-PS trial, which compared brivanib with placebo failed to give a significant increase in OS. ${ }^{125}$

Axitinib. It is a selective Tyrosine Kinase Inibitor of VEGFR-1,-2 and -3. Results of a clinical trial of 202 patients showed no significant improve in OS in comparison with sorafenib. ${ }^{126}$

Sunitinib. Sunitinib, a multitargeted tyrosine kinase inhibitor, have been used in the treatment of HCC. Cheng et al. performed a phase III clinical trial on 1074 patients due to compare sorafenib and sunitinib. Their results showed no significant difference between OS in two groups while AEs of sunitinib were higher. ${ }^{127}$

Linifanib. Linifanib is a new ATP-competitive inhibitor of all VEGF and PDGF receptor tyrosine kinases, which presents no activity against representative cytosolic tyrosine kinases and serine/threonine kinase. ${ }^{128} \mathrm{~A}$ phase III randomized clinical study on 1035 patients from 28 countries was performed to compare the efficacy and tolerability of linifanib versus sorafenib. The results showed similar OS of sorafenib and linifanib. Sorafenib showed more safety than linifanib but TTP and ORR advocated linifanib. ${ }^{128}$

\section{MET-TKI}

Tivantinib. Tivantinib, a C-MET TK inhibitor, is used as a second line therapy of HCC in clinical trials. This drug is used as monotherapy and also in combination with sorafenib. In both types of monotherapy and in combination with sorafenib, safety results were acceptable. ${ }^{129}$ Combination of tivantinib and sorafenib in phase II clinical trial turned back sorafenib resistance. ${ }^{130}$ In another phase II clinical trial of tivantinib, survival and disease control, increased and AEs of the drug were manageable in addition, grade 3 neutropenia and myelotoxicity were observed as the side effects in some studies. ${ }^{130}$

Cabozantinib. A randomized phase II trial used this drug as the second-line therapy. Results showed median OS as 15.1 months and DCR as $68 \%{ }^{132}$

\section{Monoclonal Antibodies}

Bevacizumab. Bevacizumab attaches to VEGF-A which is the main form of VEGF in blood. Two phase II trial studies have been done in order to assess this monoclonal antibody effect on HCC. ORR was $13 \%$ and $14 \%$ interestingly, but this drug failed to develop because of safety concerns. ${ }^{133,134}$

Ramucirumab. It is a human IgG1 monoclonal antibody. Ramucirumab targets VEGFR-2. In the REACH phase III trial on 565 patients, no significant OS improvement was observed except in patients with alpha fetoprotein (AFP) levels more than $400 \mathrm{ng} / \mathrm{mL} .^{135}$

\section{Chemotherapy}

Doxorubicin. Doxorubicin has been recently compared to the oxaliplatin-flourouracil (FOLFOX regimen) combination in a phase III trial. OS benefits extended ( 6.5 versus 4.9 months) in the FOLFEX arm and ORR was significantly higher $(8.2 \%$ versus $2.7 \%){ }^{114}$

GEMOX (gemcitabine plus oxaliplatin). Results of several phase II clinical trial studies showed that ORR (20\%) and DCR $(65 \%)$ were extended and drug safety profile was favorable. ${ }^{136}$ 


\section{Immunotherapy}

Tremelimumab. Anti-CTLA4 monoclonal antibody, tremelimumab, is a novel immune-based therapy used in HCC patients. In addition to good safety profile, this drug showed acceptable ORR and DCR ( $18 \%$ and $76 \%$ respectively). ${ }^{137}$

\section{PD-1 Blocking Antibodies}

Viral therapy. JX-594 has currently been used in a phase II study as an immunotherapeutic and oncolytic vaccine. High dose levels of this vaccine showed longer OS in comparison of low dose levels. ${ }^{138}$

Lenalidomide. A phase II trial study has been tested Lenalidomide-a thalidomide analogue- in advanced HCC patients after sorafenib failure. Median OS and PFS were 7.6 and 3.6 months, respectively. ${ }^{139}$

TGF-b inhibitors. TGF-b inhibitor was conducted on 109 patients in a phase II trial. Median OS and TTP were 9 and 3 months, respectively. ${ }^{140}$

\section{A. Personalized Therapy}

Two different strategies can be used in this approach:

\section{Liquid biopsy}

Plasma DNA. We can identify cancer-associated changes by using both of these methods. Detection of point mutations, detection of aberrant DNA methylation, and the detection of chromosomal aberrations are detailed methods of molecularchange identification. ${ }^{141}$

\section{Combination Therapies and Their Comparison}

\section{Combination of Minimally Invasive Therapies}

Iodine-125 implantation plus radiofrequency ablation.

Radiation therapy needs oxygen to destroy tumour cells. However, in the center of a tumour, lack of oxygenation reduces the effects of this therapy. This would be solved by heating the tumour area which makes more blood supply and more oxygenation. ${ }^{142}$ In a clinical trial of 136 patients, combination of radiofrequency ablation and iodine-125 implantation was evaluated. This combination therapy reduced the rate of recurrence $(P=0.004)$. The combination group had better results in survival rate than RFA-only group. The result of this study showed that the combination of iodine-125 and RFA would be an efficient option for patient with small HCC. ${ }^{143}$

\section{Combination of RFA and CIK}

It was reported that hyperthermia can cause stimulation and activation of the immune system. ${ }^{144}$ In a clinical trial, 62 patients with primary HCC (ranged in diameter from 2 to 8 ) were enrolled. This combination was compared with RFA alone. All the complications were related to RFA. Examined therapy had a better PFS rate $(P<0.0001)$. The risk of recurrence rate was significantly lower for new therapy $(\mathrm{HR}=0.136$, 95\% CI: 0.049-0.379). The function of liver in combination group did not change and had the same functionality before CIT infusion. Based on the results of that study, the combination of CIK and RFA was a promising treatment for HCC. ${ }^{145}$ In a clinical trial by Wang $\mathrm{X}$ et al, the combination of CIK and RF hyperthermia was evaluated. Thirty one patients with advanced HCC were enrolled. In this study instead of intravenous perfusion of $\mathrm{CIK}$, the investigators use intraperitoneal perfusion of cytokine, because it leads CIK in to tumour tissue and makes the treatment more effective. Median TTP was 6.1 months and median OS was 8.5 months. The results showed that this combination therapy was an effective therapeutic choice for patients with advanced HCC. ${ }^{146}$

\section{Radiofrequency Hyperthermia and Conformal Radiotherapy}

Assessing the combination of radiotherapy and hyperthermia is a field of interest. Conformal radiotherapy elevates the dose of irradiation in tumour and decrease receiving doses in normal tissue of the liver and cause low damage to normal tissue. Also, hyperthermia causes more blood flow to the tumour tissue, which has an additive effect on the outcome of radiotherapy. ${ }^{142}$ In study by Dong Y, short and long term of radiofrequency hyperthermia combined with conformal radiotherapy was investigated. Data were collected from 80 patients with primary advanced HCC. The patients were randomly assigned into two groups: experimental group and control group, each with 40 patients. Bilirubin, albumin, ALT and PT levels were the same between two groups before the treatments. However, after treatments bilirubin, ALT and PT were reduced more significantly in the experimental group $(P<0.05)$. Albumin was elevated in both groups but this change was significant in experimental group $(P<0.05)$. Combined therapy was much more effective than the other therapy $(P<0.001)$. Follow-up results demonstrated that the experimental group had significantly better OS and also lower recurrence rate $(P<0.001)$. Based on these results, the combination of radiofrequency hyperthermia and conformal radiotherapy has low damage to the liver and it is an effective treatment option for advanced HCC patients. ${ }^{147}$

\section{Percutaneous Ethanol Injection and Radiofrequency Ablation}

$\mathrm{Li}$ et al, in meta-analysis compared the combination of PEI + RFA with PEI and RFA as monotherapy. This study analysed the results of 13 studies from different parts of the world. First of all in this study RFA and PEI were compared. Results showed that RFA has better function than PEI in improving OS. Recurrence rate did not have significant difference in two therapies. On the other hand, PEI shows more complete tumour necrosis than RFA. In comparison of combination of these two therapies with themselves, overall the combination therapy shows better results than RFA. In spite of good result in complete tumour necrosis for combination group, this difference is not significant. ${ }^{148}$

\section{Chemotherapy and Minimally Invasive Ablative Therapies}

TACE and RFA. In a study effectiveness of a combined therapy of RFA and DEB-TACE was compared with the DEB-TACE procedure alone in treatment of single HCC. CR at 1 month was achieved in $80 \%$ of tumours. The group treated with the combination therapy showed a significantly lower 2-year recurrence (48.1\% vs. $78.2 \%, P<0.001)$ and significantly higher survival $(91.1 \%$ vs. $60.6 \%, P=0.004)$ than the group treated with DEBTACE alone. ${ }^{149}$ In a retrospective analysis of 20 patients with intermediate size HCC, the combination of DEB-TACE and MR-guided RFA was evaluated. All of the cases had child-Pugh class A and B liver function, no tumour metastasis and HCC with tumour size $>3 \mathrm{~cm}$. No major therapy-related complications were observed except for a sub capsular hepatoma which was seen in one patient right after the RFA. Median OS was 37.4 months. This combination seemed to be an effective therapy for patients with medium size HCC. ${ }^{150}$

TACE and CIK and RFA. Retrospective analysis of patients with HCC showed that RFA + CIK + TACE had more 

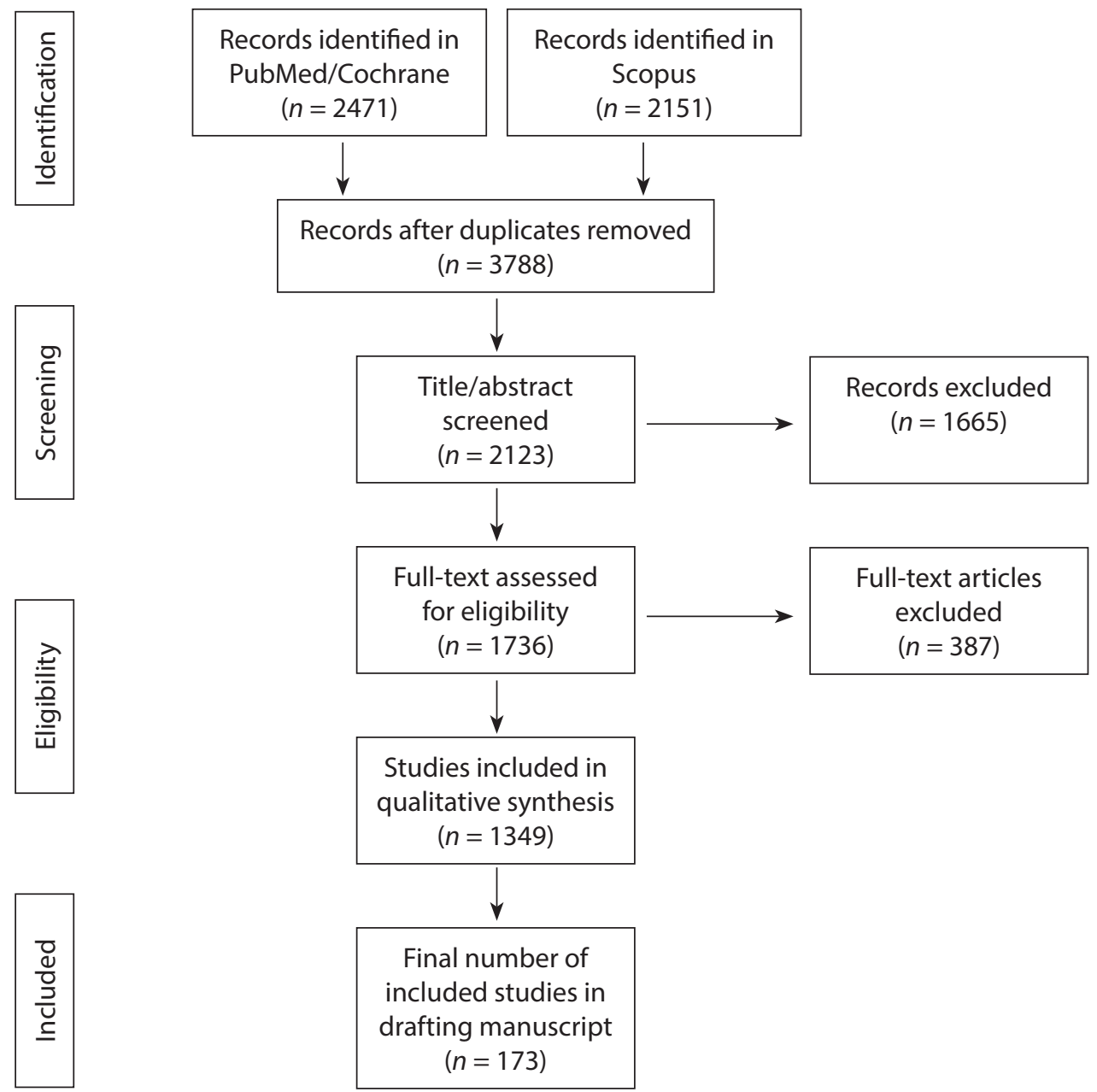

Fig. 1 The flowchart depicts the selection of studies for this review.

acceptable effect than RFA + TACE. Median survival time (ST) for the study group and the control group were 56 and 31 months, respectively which is statistically meaningful $(P=0.023)$. The results of this study demonstrated that CIK lower the risk of metastasis and recurrence in the study group and can improve the outcome of TACE + RFA. ${ }^{151}$

TACE and PVE and survival. In one RCT, 62 patients were divided into two groups, a group which had a combination of TACE and PVE and HIFU as a therapy and the other group had a combination TACE and PVE as a therapy. Nausea and vomiting were reported as a main side effect in both groups. However, in the experimental group after HIFU local pain was seen as a side effect in most of the cases. Response rate became $72 \%$ after adding HIFU to the therapy. This rate was higher than the response rate in control group (44\%). Also, controlling time of HCC in study group was higher than the control group. Median survival for experimental and control group were 16 months and 10 months respectively. Also, the level of AFP was decreased in both groups, but in experimental group this happened in lesser scale than the control group and had significant difference $(P<0.01)$. This combination is a safe and effective treatment for advanced HCC..$^{152}$

\section{Chemotherapy and Radiotherapy}

One RCT conducted by Bush, et al. compared proton beam radiotherapy with TACE in treatment for HCC. Thirty six patients in TACE group received at least one TRACE with additional TRACE for persistent disease and were treated with a mixture of ethiodol, carboplatin and doxorubicin with or without mitomycin. Thirty three patients in proton beam treatment group received the therapy to all parts of gross disease to a dose of $70.2 \mathrm{~Gy}$. The 2-year OS for both groups was 59\%. Median ST was 30 months (95\% CI: 20.7-39.3 months). PFS survival was more in the proton beam treatment group ( $48 \%$ vs. $31 \%, P=0.06) .{ }^{153}$ In a meta-analysis conducted by Lobo, et al. clinical outcomes of transarterial radioembolization (TARE) and TACE in treatment of unresectable HCC were compared. In TACE group, 284 patients were injected chemotherapy into their liver tumours, while 269 patients in TARE group had an injection of $\beta$-emitting Yttrium-90. No significant difference was observed in survival for up to 4 years between the two groups ( $\mathrm{HR}=1.06$; 95\% CI: 0.81-1.46, $P=0.567)$. The patient treated with TACE needs at least one day of hospital stay, while TARE is an outpatient procedure. ${ }^{154}$ In another meta-analysis by Zhang $\mathrm{Y}$ et al, different results were observed. They believed that TARE with Yttrium-90 had better OS, TTP and lower hospitalization time over TACE ${ }^{155}$ In a clinical trial, Jun $\mathrm{Ma}$ et al, evaluated the combination of TACE and Licartin on 341 patients. The major side effect of therapy in study group was thrombocytopenia, leucopenia and increased total bilirubin. All of the cases had stage III or IV HCC. It was reported that the efficacy of this combination therapy was higher in stage III patients. Researchers suggested this combination as a treatment for HCC patients. ${ }^{156}$ In another 
trial, this combination had acceptable outcomes for intermediate stage HCC and it was suggested as a therapeutic option for this stage. ${ }^{157}$ In another study efficacy of the combination of TACE and brachytherapy was compared to TACE alone. The study group had combination of loboplatin-TACE and ${ }^{125}$ I seeds as radiotherapy. DCR was higher in the study group $(P<0.05)$. Mean ST was 22.9 months for study group and 19.6 months for control group. Fever, pain and discomfort in liver area, nausea and vomiting and mild diarrhea were common complications in both groups. However, in the study group after ${ }^{125} \mathrm{I}$ implantation, liver function abnormalities and varying degrees of bone marrow suppression were observed. In this study, liver damage was low in the study group. This combination has efficacy for advanced HCC. ${ }^{158}$ In another study combination of (DEBs)-based TACE and SBRT was evaluated. OS was remarkably higher in the TACE + SBRT group compared with the TACE-only group (33 and 20 months, respectively; $P=0.02$ ). It can be a treatment for $\mathrm{HCC}$ with $>3 \mathrm{~cm}$ tumour size. ${ }^{159}$ In a retrospective study the effect of the combination of TACE + 3-DCRT + HIFU was evaluated. After the combination of TACE and 3-DCRT, HIFU was administered. Median ST and TTP were 26 and 9 months, respectively. Toxicity of this procedure was more common in cases with HBV and cirrhotic liver. Hepatic toxicities, gastrointestinal bleeding, and leukopenia were the major therapy-related toxicity of this combination, however for HIFU first- and second-degree skin burn were reported as major toxicity. This therapy is suggested for patients with unrespectable HCC. ${ }^{160}$

\section{TACE and Gene Therapy}

In two retrospective studies, the combination of adenovirus type 5 and TACE was compared to TACE monotherapy. Combination group had a better CR, PR and stable disease rate than monotherapy. In addition, this combination causes improvement in OS and PFS. It can be considered as an option for unresectable HCC. ${ }^{6,161}$

\section{Systemic therapy and Chemotherapy}

\section{Sorafenib and Chemotherapy}

Recent studies have compared the effect of HIAC and sorafenib on advanced HCC. Results demonstrated that the median OS was better in HIAC-treated patients. HIAC can be a rational choice for patients with advanced HCC. ${ }^{162,163}$ However, it was observed that in cases with micro vascular invasion, sorafenib had a better outcome. ${ }^{163}$ In a phase II trial by Cosgrove et al, safety and efficacy of sorafenib and DEB-TACE was evaluated. Fifty patients were enrolled. Most of them were male and had BCLC stage C HCC. Median survival for BCLC stages A, B and $C$ was 45.6, 29.7 and 8 months, respectively. Cases within BCLC stage C HCC who had sorafenib therapy for more than 6 months had better ST. Complications of this combination were mostly related to sorafenib. The results demonstrated that this combination had safety and efficacy for patients with HCC, especially in cases with advanced HCC. ${ }^{164}$

\section{Other Systemic Therapies and TACE}

In a clinical trial of 26 patients, the combination of Bevacizumab and TACE was evaluated. In this study, all of the cases had BCLC stage B or C HCC. In this study, median survival was 10.8 months. The result of this study demonstrated that this combination was an effective therapy for unresectable HCC. ${ }^{165}$ In a retrospective analysis of 103 patients, combination of sunitinib and TACE was assessed. Based on the results, this combination therapy elongates the survival period and postpones tumour progression and can be an option for advanced HCC. ${ }^{166}$

\section{Sorafenib and RFA}

In a retrospective study the effect of Sorafenib and RFA was compared with RFA alone. Data were collected from 128 patients who had HCC within BCLC stage 0 to B1. Patients were equally divided in two groups. Sorafenib was administered after the RFA procedure. The recurrence rate was lower in the combination group. Median OS for RFA-sorafenib group and RFA group were 161.8 and 118.6 weeks, respectively. This combination reduced the recurrence rate. It may be an efficient therapeutic option for inoperable HCC. ${ }^{167}$ In RCT the effect of Sorafenib and percutaneous radiofrequency ablation was examined. In another study, 62 patients were enrolled, and it was demonstrated that the effect of combination therapy was more efficient for medium-size HCC than RFA alone. This study showed the same results about recurrence rate. ${ }^{168}$

\section{Systemic Therapy and Radiotherapy}

Radiotherapy and sorafenib. Nakazawa, et al. conducted a study to evaluate sorafenib and RT used in the treatment of unresectable HCC with major PVTT. OS was compared between cases with PVTT. There is no significant difference in the median survival ( 4.3 vs. 5.9 months; $P=0.115$ ). After the propensity score matching ( $n=28$ per group), better survival was observed in the RT group than in the sorafenib group (median survival, 10.9 vs. 4.8 months; $P=0.025) .{ }^{169}$ In another study YANG Y, et al evaluated the effect of cryotherapy plus sorafenib as a combination therapy for patients with advanced HCC. A total of 296 patients with HBV-related HCC in advance stage were enrolled and follow up for 2 years. The authors believe that the curative mechanism of sorafenib had a synergic effect on the effect of local cryoRx. Median OS was 12.5 months for cases in the combination group while median OS for sorafenib-only group was 8.6 months. This combination is safe and effective therapy for advanced HCC. ${ }^{170}$

Sorafenib and Radioembolization. Radiation causes activation of intracellular signaling pathway. Also, it causes the increasing of VEGF in the body. In a phase two clinical trial of 29 HCC cases within BCLC stage B and C, safety and efficacy of the sorafenib plus radiembolization was examined. For radiormbolization a form of brachytherapy, 90Y-microsphere was administered. Twenty five percent of cases showed the best overall response and among these cases, $28 \%$ showed CR. Median OS for cases in BCLC stage B was 15.2 months and for BCLC stage C was 6.5 months. The results of this study confirmed this combination as a safe and efficient option for advanced HCC. ${ }^{171}$

Surgical resection and minimally invasive ablative therapies. For small HCC, mainly there are two different therapeutic options. One of them is RFA and the other one is surgical resection (SR). ${ }^{172,173}$ In recent meta-analyses, it has shown that for small HCC $(\leq 3 \mathrm{~cm})$, SR is more efficient than RFA. ${ }^{172,173}$ In small HCC the one-, three- and five-year OS rate is higher in patients who had SR as a treatment option. ${ }^{172,173}$ The rate of local recurrence of HCC in SR group was lower than RFA group. ${ }^{173}$ Also, for single nodular HCC, SR will be a suitable choice but for multi nodular HCC, RFA is a better choice, because of surgical complications. ${ }^{172}$ Performing RFA 
by laparoscopic approach shows similar results in OS of patients as SR but the rate of local recurrence of HCC is still higher. ${ }^{173}$

\section{Conclusion}

In summary, recent changes in managing of HCC have shown a trend in using minimally invasive and noninvasive options instead of hepatic resection and transplantation. New technologies in ablative devices, radiotherapy and chemotherapy have improved the accuracy and efficacy of these treatments. In addition, using immune system, gene therapy and new targeted therapy agents have shown the high potential of cellular and molecular mechanisms in managing HCC. However, more RCTs are needed to evaluate the effect of these therapies. Moreover, the combination of different sort of therapy has become popular recently. Many researchers all over the world have reported the benefit of the majority of these combinations. However, in these cases more studies are needed to prove the advantage of this kind of therapy over current curative options.

\section{Conflict of Interest}

No one of the authors have any conflict of interest.

\section{References}

1. Ferlay J, Soerjomataram I, Dikshit R, Eser S, Mathers C, Rebelo M, et al. Cancer incidence and mortality worldwide: sources, methods and major patterns in GLOBOCAN 2012. Int J Cancer. 2015;136:E359-E386.

2. Wallace MC, Preen D, Jeffrey GP, Adams LA. The evolving epidemiology of hepatocellular carcinoma: a global perspective. Expert Rev Gastroenterol Hepatol. 2015;9:765-779.

3. Bruix J, Gores GJ, Mazzaferro V. Hepatocellular carcinoma: clinical frontiers and perspectives. Gut. 2014:63:844-855.

4. Forner A, Llovet JM, Bruix J. Hepatocellular carcinoma. Lancet. 2012;379: $1245-1255$.

5. Aerts M, Benteyn D, Van Vlierberghe H, Thielemans K, Reynaert H. Current status and perspectives of immune-based therapies for hepatocellular carcinoma. World J Gastroenterol. 2016;22:253-261.

6. Dong J, Li W, Dong A, Mao S, Shen L, Li S, et al. Gene therapy for unresectable hepatocellular carcinoma using recombinant human adenovirus type 5. Med Oncol. 2014;31.

7. Wei Z, Doria C, Liu Y. Targeted therapies in the treatment of advanced hepatocellular carcinoma. Clinical Medicine Insights Oncology. 2013;7:87-102

8. Zhu AX. Systemic therapy of advanced hepatocellular carcinoma: how hopeful should we be?. The oncologist. 2006;11:790-800.

9. Lai CL, Wu PC, Chan GC, Lok AS, Lin HJ. Doxorubicin versus no antitumor therapy in inoperable hepatocellular carcinoma. A prospective randomized trial. Cancer. 1988;62:479-483.

10. Petrelli F, Coinu A, Borgonovo K, Cabiddu M, Ghilardi M, Lonati V, et al. Oxaliplatin-based chemotherapy: a new option in advanced hepatocellular carcinoma. a systematic review and pooled analysis. Clin Oncol. 2014;26: 488-496.

11. Qin S, Bai Y, Lim HY, Thongprasert S, Chao Y, Fan J, et al. Randomized, multicenter, open-label study of oxaliplatin plus fluorouracil/leucovorin versus doxorubicin as palliative chemotherapy in patients with advanced hepatocellular carcinoma from Asia. J Clin Oncol. 2013;31:3501-3508.

12. Bruix J, Sherman M. Management of hepatocellular carcinoma. Hepatology. 2005:42:1208-1236.

13. Paul SB, Sharma H. Role of transcatheter intra-arterial therapies for hepatocellular carcinoma. J Clin Exp Hepatol. 2014:4:S112-S121.

14. Riemsma RP, Bala MM, Wolff R, Kleijnen J. Transarterial (chemo)embolisation versus no intervention or placebo intervention for liver metastases. Cochrane Database Syst Rev. 2013:CD009498.

15. European Association For The Study Of The Liver, European Organisation For Research And Treatment Of Cancer. EASL-EORTC clinical practice guidelines: management of hepatocellular carcinoma. J Hepatol. 2012;56:908-943.

16. Zhao Y, Cai G, Zhou L, Liu L, Qi X, Bai M, et al. Transarterial chemoembolization in hepatocellular carcinoma with vascular invasion or extrahepatic metastasis: a systematic review. Asia Pac J Clin Oncol. 2013:9:357-364.

17. Xie ZB, Ma L, Wang XB, Bai T, Ye JZ, Zhong JH, et al. Transarterial embolization with or without chemotherapy for advanced hepatocellular carcinoma: a systematic review. Tumour Biol. 2014;35:8451-8459.

18. Ogawa M, Takayasu K, Hirayama M, Miura T, Shiozawa K, Abe M, et al. Efficacy of a microballoon catheter in transarterial chemoembolization of hepatocellular carcinoma using miriplatin, a lipophilic anticancer drug: short-term results. Hepatol Res. 2016:46:E60-E69.

19. Tawada A, Chiba T, Ooka Y, Kanogawa N, Saito T, Motoyama T, et al. Transarterial chemoembolization with miriplatin plus epirubicin in patients with hepatocellular carcinoma. Anticancer Res. 2015;35:549-554

20. Lewis AL, Gonzalez MV, Lloyd AW, Hall B, Tang Y, et al. DC bead: in vitro characterization of a drug-delivery device for transarterial chemoembolization. JVasc Interv Radiol. 2006;17:335-342.
21. Huang K, Zhou Q, Wang R, Cheng D, Ma Y. Doxorubicin-eluting beads versus conventional transarterial chemoembolization for the treatment of hepatocellular carcinoma. J Gastroenterol Hepatol. 2014;29:920-925.

22. Lammer J, Malagari K, Vogl T, Pilleul F, Denys A, Watkinson A, et al. Prospective randomized study of doxorubicin-eluting-bead embolization in the treatment of hepatocellular carcinoma: results of the PRECISION V study. Cardiovasc Intervent Radiol. 2010;33:41-52.

23. Sacco R, Bargellini I, Bertini M, Bozzi E, Romano A, Petruzzi P, et al. Conventional versus doxorubicin-eluting bead transarterial chemoembolization for hepatocellular carcinoma. J Vasc Interv Radiol. 2011:22:1545-1552

24. Wiggermann P, Sieron D, Brosche C, Brauer T, Scheer F, Platzek I, et al. Transarterial chemoembolization of Child-A hepatocellular carcinoma: drug-eluting bead TACE (DEB TACE) vs. TACE with cisplatin/lipiodol (CTACE). Med Sci Monit. 2011;17:CR189-CR195.

25. Song MJ, Chun HJ, Kim HY, Yoo SH, Park CH, Bae SH, et al. Comparative study between doxorubicin-eluting beads and conventional transarterial chemoembolization for treatment of hepatocellular carcinoma. J Hepatol. 2012;57:1244-1250.

26. Kloeckner R, Weinmann A, Prinz F, Pinto dos Santos D, Ruckes C, Dueber C, et al. Conventional transarterial chemoembolization versus drug-eluting bead transarterial chemoembolization for the treatment of hepatocellular carcinoma. BMC Cancer. 2015;15:465.

27. Gao S, Yang Z, Zheng Z, Yao J, Deng M, Xie H, et al. Doxorubicin-eluting bead versus conventional TACE for unresectable hepatocellular carcinoma: a meta-analysis. Hepato-gastroenterol. 2013;60:813-820.

28. Katsumori T, Kasahara T. The size of gelatin sponge particles: differences with preparation method. Cardiovasc Intervent Radiol. 2006;29:1077-1083.

29. Wu PZ, Zhou J, Zhang YW. Gelatin sponge microparticles for the treatment of the spontaneous rupture of hepatocellular carcinoma hemorrhage. Exp Therap Med. 2016:12:2201-2207.

30. de Baere T, Arai Y, Lencioni R, Geschwind JF, Rilling W, Salem R, et al. Treatment of liver tumors with lipiodol tace: technical recommendations from experts opinion. CardioVasc Intervent Radiol. 2016;39:334-343.

31. Zhang YW, Ao J, Liu Y, Qiao MX, Yang XL, Tang SX, et al. Pharmacokinetics of gelatin sponge microparticles in a rabbit VX2 liver tumor model of hepatic arterial chemoembolization. Tumor Biol. 2014;35:10905-10910.

32. Kamran AU, Liu Y, Li FE, Liu S, Wu JL, Zhang YW. Transcatheter arterial chemoembolization with gelatin sponge microparticles treated for $B C L C$ stage $B$ hepatocellular carcinoma: a single center retrospective study. Medicine (Baltimore). 2015;94:e2154.

33. Qi X, Wang D, Su C, Li H, Guo X. Hepatic resection versus transarterial chemoembolization for the initial treatment of hepatocellular carcinoma: a systematic review and meta-analysis. Oncotarget. 2015:6:18715-18733

34. Kapitanov T, Neumann UP, Schmeding M. Hepatocellular carcinoma in liver cirrhosis: surgical resection versus transarterial chemoembolization-a metaanalysis. Gastroenterol Res Pract. 2015;2015:696120.

35. He G, Zheng $\mathrm{C}$, Huo H, Zhang H, Zhu Z, Li J, et al. TACE combined with dendritic cells and cytokine-induced killer cells in the treatment of hepatocellular carcinoma: a meta-analysis. Int Immunopharmacol. 2016:40:436-442

36. Mesiano G, Todorovic M, Gammaitoni L, Leuci V, Giraudo Diego L, Carnevale-Schianca F, et al. Cytokine-induced killer (CIK) cells as feasible and effective adoptive immunotherapy for the treatment of solid tumors. Exp Opin Biol Ther. 2012;12:673-684.

37. Rude MK, Crippin JS. Liver transplantation for hepatocellular carcinoma. Curr Gastroenterol Rep. 2015;17:1-5. 
38. O'Grady J. Liver transplantation. Medicine (United Kingdom). 2015;43:686-688.

39. Sheth RA, Patel MS, Koottappillil B, Shah JA, Oklu R, Mueller P, et al. Role of locoregional therapy and predictors for dropout in patients with hepatocellular carcinoma listed for liver transplantation. J Vasc Interv Radiol. 2015;26:1761-1768; quiz 1768.

40. Na GH, Kim EY, Hong TH, You YK, Kim DG. Effects of loco regional treatments before living donor liver transplantation on overall survival and recurrencefree survival in South Korean patients with hepatocellular carcinoma. HPB (Oxford). 2016;18:98-106.

41. Teng F, Wang GH, Tao YF, Guo WY, Wang ZX, Ding GS, et al. Criteria-specific long-term survival prediction model for hepatocellular carcinoma patients after liver transplantation. World J Gastroenterol. 2014;20:10900-10907.

42. Paredes AH, Satoskar R. Hepatocellular carcinoma: when to transplant outside of Milan criteria. Curr Hepat Rep. 2013;12:37-46.

43. Kudo M, Izumi N, Kokudo N, Matsui O, Sakamoto M, Nakashima O, et al. Management of hepatocellular carcinoma in Japan: Consensus-based clinical practice guidelines proposed by the Japan Society of Hepatology (JSH) 2010 updated version. Dig Dis. 2011;29:339-364.

44. Poon RT, Fan ST, Lo CM, Liu CL, Wong J. Long-term survival and pattern of recurrence after resection of small hepatocellular carcinoma in patients with preserved liver function: implications for a strategy of salvage transplantation. Ann Surg. 2002;235:373-382.

45. Felli E, Cillo U, Pinna AD, De Carlis L, Ercolani G, Santoro R, et al. Salvage liver transplantation after laparoscopic resection for hepatocellular carcinoma: a multicenter experience. Updates in Surgery. 2015;67:215-222.

46. Zhu Y, Dong J, Wang WL, Li MX, Lu Y. Short- and long-term outcomes after salvage liver transplantation versus primary liver transplantation for hepatocellular carcinoma: a meta-analysis. Transplant Proc. 2013;45:3329-3342.

47. Rao A, Rao G, Ahmed I. Laparoscopic vs. open liver resection for malignant liver disease. A systematic review. Surgeon. 2012;10:194-201.

48. Bruix J, Sherman M. Management of hepatocellular carcinoma: an update. Hepatology. 2011;53:1020-1022.

49. Dahiya D, Wu TJ, Lee CF, Chan KM, Lee WC, Chen MF. Minor versus major hepatic resection for small hepatocellular carcinoma (HCC) in cirrhotic patients: a 20-year experience. Surgery. 2010;147:676-685.

50. Arii S, Tanaka S, Mitsunori Y, Nakamura N, Kudo A, Noguchi N, et al. Surgical strategies for hepatocellular carcinoma with special reference to anatomical hepatic resection and intraoperative contrast-enhanced ultrasonography. Oncology. 2010;78:125-130.

51. Zhou Y, Xu D, Wu L, Li B. Meta-analysis of anatomic resection versus nonanatomic resection for hepatocellular carcinoma. Langenbecks Arch Surg. 2011;396:1109-1117.

52. Liu PH, Lee YH, Hsu CY, Hsia CY, Huang YH, Chiou YY, et al. Surgical resection is better than transarterial chemoembolization for hepatocellular carcinoma beyond Milan criteria independent of performance status. J Gastrointest Surg. 2014;18:1623-1631

53. Topal B, Fieuws S, Aerts R, Vandeweyer H, Penninckx F. Laparoscopic versus open liver resection of hepatic neoplasms: comparative analysis of shortterm results. Surg Endosc. 2008;22:2208-2213.

54. Santambrogio R, Bruno S, Kluger MD, Costa M, Salceda J, Belli A, et al. Laparoscopic ablation therapies or hepatic resection in cirrhotic patients with small hepatocellular carcinoma. Dig Liver Dis. 2016;48:189-196.

55. Lencioni R. Loco-regional treatment of hepatocellular carcinoma. Hepatology. 2010;52:762-773.

56. Crocetti L, De Baere T, Lencioni R. Quality improvement guidelines for radiofrequency ablation of liver tumours. Cardiovasc Intervent Radiol. 2010;33:11-17.

57. Vouche M, Habib A, Ward TJ, Kim E, Kulik L, Ganger D, et al. Unresectable solitary hepatocellular carcinoma not amenable to radiofrequency ablation: multicenter radiology-pathology correlation and survival of radiation segmentectomy. Hepatology. 2014;60:192-201.

58. Padia SA, Kwan SW, Roudsari B, Monsky WL, Coveler A, Harris WP. Superselective yttrium-90 radioembolization for hepatocellular carcinoma yields high response rates with minimal toxicity. J Vasc Interv Radiol. 2014;25:1067-1073.

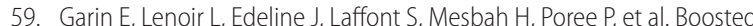
selective internal radiation therapy with 90Y-loaded glass microspheres (B-SIRT) for hepatocellular carcinoma patients: a new personalized promising concept. Eur J Nucl Med Mol Imaging. 2013;40:1057-1068.

60. Garin E, Lenoir L, Rolland Y, Edeline J, Mesbah H, Laffont S, et al. Dosimetry based on 99mTc-macroaggregated albumin SPECT/CT accurately predicts tumor response and survival in hepatocellular carcinoma patients treated with 90Y-loaded glass microspheres: preliminary results. J Nucl Med. 2012;53:255-263.
61. Garin E, Rolland Y, Edeline J, Icard N, Lenoir L, Laffont S, et al. Personalized dosimetry with intensification using 90Y-loaded glass microsphere radioembolization induces prolonged overall survival in hepatocellular carcinoma patients with portal vein thrombosis. J Nucl Med. 2015;56:339-346.

62. IMRT therapy collaborative working group. Intensity-modulated radiotherapy: current status and issues of interest. International Journal of Radiation Oncology, Biology, Physics. 2001;51:880-914.

63. Mackie TR, Holmes T, Swerdloff S, Reckwerdt P, Deasy JO, Yang J, et al. Tomotherapy: a new concept for the delivery of dynamic conformal radiotherapy. Med Phys. 1993;20:1709-1719.

64. Kim JY, Yoo EJ, Jang JW, Kwon JH, Kim KJ, Kay CS. Hypofractionated radiotheapy using helical tomotherapy for advanced hepatocellular carcinoma with portal vein tumor thrombosis. Radiat Oncol. 2013;8.

65. Jung J, Kong M, Hong SE. Conventional fractionated helical tomotherapy for patients with small to medium hepatocellular carcinomas without portal vein tumor thrombosis. Onco Targets Ther. 2014;7:1769-1775.

66. Yoon HI, Lee IJ, Han KH, Seong J. Improved oncologic outcomes with image-guided intensity-modulated radiation therapy using helical tomotherapy in locally advanced hepatocellular carcinoma. J Cancer Res Clin Oncol. 2014;140:1595-1605.

67. Hou JZ, Zeng ZC, Wang BL, Yang P, Zhang JY, Mo HF. High dose radiotherapy with image-guided hypo-IMRT for hepatocellular carcinoma with portal vein and/or inferior vena cava tumor thrombi is more feasible and efficacious than conventional 3D-CRT. Jpn J Clin Oncol. 2016;46:357-362.

68. Otto K. Volumetric modulated arc therapy: IMRT in a single gantry arc. Med Phys 2008;35:310-317.

69. Gong GZ, Yin Y, Xing LG, Guo YJ, Liu T, Chen J, et al. RapidArc combined with the active breathing coordinator provides an effective and accurate approach for the radiotherapy of hepatocellular carcinoma. Strahlenther Onkol. 2012;188:262-268.

70. Gong G, Yin Y, Guo Y, Liu T, Chen J, Lu J, et al. Dosimetric differences among volumetric modulated arc radiotherapy (RapidArc) plans based on different target volumes in radiotherapy of hepatocellular carcinoma. J Radiat Res. 2013;54:182-189.

71. Potters L, Kavanagh B, Galvin JM, Hevezi JM, Janjan NA, Larson DA, Mehta MP, et al. American Society for Therapeutic Radiology and Oncology (ASTRO) and American College of Radiology (ACR) practice guideline for the performance of stereotactic body radiation therapy. Int J Radiat Oncol Biol Phys. 2010;76:326-332.

72. Thariat J, Marcié S, Marcy PY, Trimaud R, Angellier G, Mammar H, et al. [Cyberknife robotic stereotactic radiotherapy: technical aspects and recent developments]. Bull Cancer. 2010;97:807-818.

73. Oldrini G, Taste-George H, Renard-Oldrini S, Baumann AS, Marchesi V, Troufléau P, et al. Implantation of fiducial markers in the liver for stereotactic body radiation therapy: feasibility and results. Diagn Interv Imaging. 2015;96:589-592.

74. Kim JW, Seong J, Lee IJ, Woo JY, Han KH. Phase I dose escalation study of helical intensity-modulated radiotherapy-based stereotactic body radiotherapy for hepatocellular carcinoma. Oncotarget. 2016;7: 40756-40766.

75. Bowen SR, Saini J, Chapman TR, Miyaoka RS, Kinahan PE, Sandison GA et al. Differential hepatic avoidance radiation therapy: proof of concept in hepatocellular carcinoma patients. Radiother Oncol. 2015;115:203-210.

76. Beddar AS, Kainz K, Briere TM, Tsunashima Y, Pan T, Prado K, et al. Correlation between internal fiducial tumor motion and external marker motion for liver tumors imaged with 4D-CT. Int J Radiat Oncol Biol Phys. 2007:67:630-638

77. Law AL, Ng WT, Lee MC, Chan AT, Fung KH, Li F, et al. Treatment of primary liver cancer using highly-conformal radiotherapy with kV-image guidance and respiratory control. Radiother Oncol. 2012;102:56-61.

78. Kitada T, Murakami T, Kuzushita N, Minamitani K, Nakajo K, Osuga K, et al. Effectiveness of real-time virtual sonography-guided radiofrequency ablation treatment for patients with hepatocellular carcinomas. Hepatol Res. 2008;38:565-571.

79. Nakai M, Sato M, Sahara S, Takasaka I, Kawai N, Minamiguchi H, et al. Radiofrequency ablation assisted by real-time virtual sonography and $\mathrm{CT}$ for hepatocellular carcinoma undetectable by conventional sonography. Cardiovasc Intervent Radiol. 2009;32:62-69.

80. Sandulescu DL, Dumitrescu D, Rogoveanu I, Saftoiu A. Hybrid ultrasound imaging techniques (fusion imaging). World J Gastroenterol. 2011;17:49-52.

81. Lee MW, Rhim H, Cha DI, Kim YJ, Choi D, Kim YS, et al. Percutaneous radiofrequency ablation of hepatocellular carcinoma: fusion imaging guidance for management of lesions with poor conspicuity at conventional sonography. AJR Am J Roentgenol. 2012;198:1438-1444. 
82. Xu ZF, Xie XY, Kuang M, Liu GJ, Chen LD, Zheng YL, et al. Percutaneous radiofrequency ablation of malignant liver tumors with ultrasound and CT fusion imaging guidance. J Clin Ultrasound. 2014;42:321-330.

83. Goldberg SN, Solbiati L, Hahn PF, Cosman E, Conrad JE, Fogle R, et al. Large-volume tissue ablation with radio frequency by using a clustered, internally cooled electrode technique: laboratory and clinical experience in liver metastases. Radiology. 1998;209:371-379.

84. Kettenbach J, Köstler W, Rücklinger E, Gustorff B, Hüpfl M, Wolf F, et al. Percutaneous saline-enhanced radiofrequency ablation of unresectable hepatic tumors: initial experience in 26 patients. AJR Am J Roentgenol. 2003:180:1537-1545.

85. Kim JH, Kim PN, Won HJ, Shin YM. Percutaneous radiofrequency ablation using internally cooled wet electrodes for the treatment of hepatocellular carcinoma. AJR Am J Roentgenol. 2012;198:471-476.

86. Kim JH, Kim PN, Won HJ, Shin YM. Percutaneous radiofrequency ablation with internally cooled versus internally cooled wet electrodes for small subphrenic hepatocellular carcinomas. J Vasc Interv Radiol 2013:24:351-356

87. Osaki Y, Ikeda K, Izumi N, Yamashita S, Kumada H, Hatta S, et al. Clinica effectiveness of bipolar radiofrequency ablation for small liver cancers. J Gastroenterol. 2013;48:874-883.

88. Mazzaferro V, Battiston C, Perrone S, Pulvirenti A, Regalia E, Romito R, et al. Radiofrequency ablation of small hepatocellular carcinoma in cirrhotic patients awaiting liver transplantation: a prospective study. Ann Surg. 2004;240:900-909.

89. Frericks BB, Ritz JP, Roggan A, Wolf KJ, Albrecht T. Multipolar radiofrequency ablation of hepatic tumors: initial experience. Radiology 2005;237:1056-1062

90. Seror O, N'Kontchou G, Van Nhieu JT, Rabahi Y, Nahon P, Laurent A. et al. Histopathologic comparison of monopolar versus no-touch multipolar radiofrequency ablation to treat hepatocellular carcinoma within Milan criteria. J Vasc Interv Radiol. 2014;25:599-607.

91. Toyoda H, Kumada T, Tada T, Kaneoka Y, Maeda A. Placement of a sodium hyaluronate solution onto the liver surface as a supportive procedure for radiofrequency ablation of hepatocellular carcinomas located on the liver surface: a preliminary report. J Vasc Interv Radiol. 2012;23:1639-1645.e1

92. Liu FY, Yu XL, Liang P, Cheng ZG, Han ZY, Dong BW, et al. Microwave ablation assisted by a real-time virtual navigation system for hepatocellular carcinoma undetectable by conventional ultrasonography. Eur J Radiol. 2012:81:1455-1459

93. Iannitti DA, Martin RC, Simon CJ, Hope WW, Newcomb WL, McMasters KM, et al. Hepatic tumor ablation with clustered microwave antennae: the US Phase II trial. HPB (Oxford). 2007;9:120-124.

94. Ziemlewicz TJ, Hinshaw JL, Lubner MG, Brace CL, Alexander ML, Agarwal P, et al. Percutaneous microwave ablation of hepatocellular carcinoma with a gas-cooled system: initial clinical results with 107 tumors. JVasc Interv Radiol. 2015;26:62-68

95. Llovet JM, Vilana R, Brú C, Bianchi L, Salmeron JM, Boix L, et al. Barcelona Clínic Liver Cancer (BCLC) Group. Increased risk of tumor seeding after percutaneous radiofrequency ablation for single hepatocellular carcinoma. Hepatology. 2001;33:1124-1129.

96. Patel PA, Ingram L, Wilson ID, Breen DJ. No-touch wedge ablation technique of microwave ablation for the treatment of subcapsular tumors in the liver. J Vasc Interv Radiol. 2013;24:1257-1262.

97. Kim YJ, Lee MW, Park HS. Small hepatocellular carcinomas: ultrasonography guided percutaneous radiofrequency ablation. Abdom Imaging. 2013;38:98-111.

98. Kang TW, Rhim H, Lee MW, Kim YS, Choi D, Lee WJ, et al. Radiofrequency ablation for hepatocellular carcinoma abutting the diaphragm: comparison of effects of thermal protection and therapeutic efficacy. AJR Am J Roentgenol. 2011;196:907-913.

99. Kang TW, Lim HK, Lee MW, Kim YS, Choi D, Rhim H. First-line radiofrequency ablation with or without artificial ascites for hepatocellular carcinomas in a subcapsular location: local control rate and risk of peritoneal seeding at long-term follow-up. Clin Radiol. 2013;68:e641-e651.

100. Zhang D, Liang P, Yu X, Cheng Z, Han Z, Yu J, et al. The value of artificial pleural effusion for percutaneous microwave ablation of liver tumour in the hepatic dome: a retrospective case-control study. Int J Hyperthermia. 2013;29:663-670

101. Wuu C, Kliauga P, Zaider M, Amols H. Microdosimetric evaluation of relative biological effectiveness for ${ }^{103} \mathrm{Pd},{ }^{125},{ }^{241} \mathrm{Am}$, and ${ }^{192}$ Ir brachytherapy sources. Int J Radiat Oncol Biol Phys. 1996:36:689-697.
102. Ricke J, Wust P, Stohlmann A, Beck A, Cho CH, Pech M, et al. CT-guided interstitial brachytherapy of liver malignancies alone or in combination with thermal ablation: phase I-II results of a novel technique. Int J Radiat Oncol Biol Phys. 2004:58:1496-1505.

103. Collettini F, Schnapauff D, Poellinger A, Denecke T, Schott E, Berg T, et al. Hepatocellular carcinoma: computed-tomography-guided high-dose-rate brachytherapy (CT-HDRBT) ablation of large $(5-7 \mathrm{~cm})$ and very large (>7 cm) tumours. Eur Radiol. 2012;22:1101-1109.

104. Collettini F, Schreiber N, Schnapauff D, Denecke T, Wust P, Schott E, et al. CT-guided high-dose-rate brachytherapy of unresectable hepatocellular carcinoma. Strahlenther Onkol. 2015;191:405-412.

105. Wu F, Wang ZB, Chen WZ, Wang W, Gui Y, Zhang M, et al. Extracorporeal high intensity focused ultrasound ablation in the treatment of 1038 patients with solid carcinomas in China: an overview. Ultrason Sonochem. 2004;11:149-154

106. Fukuda H, Numata K, Nozaki A, Kondo M, Morimoto M, Maeda S, et al. High-intensity focused ultrasound ablation assisted using color Doppler imaging for the treatment of hepatocellular carcinomas. Abdom Imaging. 2013;38:1263-1268

107. Anzidei M, Napoli A, Sandolo F, Marincola BC, Di Martino M, Berloco P, et al. Magnetic resonance-guided focused ultrasound ablation in abdominal moving organs: a feasibility study in selected cases of pancreatic and liver cancer. Cardiovasc Intervent Radiol. 2014;37:16111617

108. Wu MC. Traditional Chinese medicine in prevention and treatment of liver cancer: function. saepJCIM-C Zhong Xi Yi Jie He Xue Bao. 2003;1(3):163-164.

109. Sun Z, Liang ST, Zhai XF, Lang QB, Zhou QH, Yue XQ, et al. A traditional Chinese herbal medicine compound preparation versus interventional therapy after resection of small hepatocellular carcinoma: 22-year followup. J Tradit Chin Med. 2012;32:156-163.

110. Jeng KS, Sheen IS, Wang YC, Gu SL, Chu CM, Shih SC, et al. Prognostic significance of preoperative circulating vascular endothelial growth factor messenger RNA expression in resectable hepatocellular carcinoma: a prospective study. World J Gastroenterol. 2004;10:643-648.

111. Ye SL, Chen X, Yang J, Bie P, Zhang S, Liu F, et al. Safety and efficacy of sorafenib therapy in patients with hepatocellular carcinoma: final outcome from the Chinese patient subset of the GIDEON study. Oncotarget. 2016:7:6639-6648.

112. Kudo M. Adjuvant therapy after curative treatment for hepatocellular carcinoma. Oncology. 2011:81:50-55.

113. Wang SN, Chuang SC, Lee KT. Efficacy of sorafenib as adjuvant therapy to prevent early recurrence of hepatocellular carcinoma after curative surgery: a pilot study. Hepatol Res. 2014;44:523-531.

114. Abou-Alfa GK, Johnson P, Knox JJ, Capanu M, Davidenko I, Lacava J, et al. Doxorubicin plus sorafenib vs doxorubicin alone in patients with advanced hepatocellular carcinoma: a randomized trial. JAMA. 2010;304:2154-2160.

115. Mir O, Coriat R, Boudou-Rouquette P, Ropert S, Durand JP, Cessot A, et al. Gemcitabine and oxaliplatin as second-line treatment in patients with hepatocellular carcinoma pre-treated with sorafenib. Med Oncol. 2012;29:2793-2799.

116. Yau TC, Cheung FY, Lee F, Choo SP, Wong H, Toh HC, et al. A multicenter phase II study of sorafenib, capecitabine, and oxaliplatin (SECOX) in patients with advanced hepatocellular carcinoma: final results of Hong Kong-Singapore hepatocellular carcinoma research collaborative group study. In: ASCO Annual Meeting Proceedings. 2013;2013. p. 4117.

117. Zhu AX, Rosmorduc O, Evans TR, Ross PJ, Santoro A, Carrilho FJ, et al. SEARCH: a phase III, randomized, double-blind, placebo-controlled trial of sorafenib plus erlotinib in patients with advanced hepatocellular carcinoma. J Clin Oncol. 2015;33:559-566.

118. Zhu AX, Kudo M, Assenat E, Cattan S, Kang YK, Lim HY, et al. Effect of everolimus on survival in advanced hepatocellular carcinoma after failure of sorafenib: the EVOLVE-1 randomized clinical trial. JAMA. 2014;312:57-67.

119. Kelley RK, Nimeiri HS, Munster PN, Vergo MT, Huang Y, Li CM, et al. Temsirolimus combined with sorafenib in hepatocellular carcinoma: a phase I dose-finding trial with pharmacokinetic and biomarker correlates. Ann Oncol. 2013:24:1900-1907.

120. Chan SL, Mo F, Hui EP, Koh J, Chu C, Hui J, et al. A phase I study of temsirolimus as novel therapeutic drug for patients with unresectable hepatocellular carcinoma (HCC). In: ASCO Annual Meeting Proceedings. 2013;2013. p. e15048.

121. Sachdev JC, Javed AY, Weir AB, Korn RI, Gulla SM, Newbold RG, et al. A phase II study of temsirolimus in previously treated advanced hepatocellular carcinoma (HCC). In: ASCO Annual Meeting Proceedings; 2014;2014. p. 4098 
122. Lim HY, Heo J, Choi HJ, Lin CY, Yoon JH, Hsu C, et al. A phase II study of the efficacy and safety of the combination therapy of the MEK inhibitor refametinib (BAY 86-9766) plus sorafenib for Asian patients with unresectable hepatocellular carcinoma. Clin Cancer Res. 2014;20:5976-5985.

123. Bruix J, Tak WY, Gasbarrini A, Santoro A, Colombo M, Lim HY, et al. Regorafenib as second-line therapy for intermediate or advanced hepatocellular carcinoma: multicentre, open-label, phase II safety study. Eur J Cancer. 2013;49:3412-3419.

124. Huynh H, Ngo VC, Fargnoli J, Ayers M, Soo KC, Koong HN, et al. Brivanib alaninate, a dual inhibitor of vascular endothelial growth factor receptor and fibroblast growth factor receptor tyrosine kinases, induces growth inhibition in mouse models of human hepatocellular carcinoma. Clin Cancer Res. 2008:14:6146-6153.

125. Johnson PJ, Qin S, Park JW, Poon RT, Raoul JL, Philip PA, et al. Brivanib versus sorafenib as first-line therapy in patients with unresectable, advanced hepatocellular carcinoma: results from the randomized phase III BRISK-FL study. J Clin Oncol. 2013;31:3517-3524.

126. Kang YK, Yau T, Park JW, Lim HY, Lee TY, Obi S, et al. Randomized phase Il study of axitinib versus placebo plus best supportive care in secondline treatment of advanced hepatocellular carcinoma. Ann Oncol. 2015;26:2457-2463.

127. Cheng AL, Kang YK, Lin DY, Park JW, Kudo M, Qin S, et al. Sunitinib versus sorafenib in advanced hepatocellular cancer: results of a randomized phase III trial. J Clin Oncol. 2013;31:4067-4075.

128. Cainap C, Qin S, Huang WT, Chung IJ, Pan H, Cheng Y, et al. Linifanib versus sorafenib in patients with advanced hepatocellular carcinoma: results of a randomized phase III trial. J Clin Oncol. 2015:33:172-179.

129. Trojan J, Zeuzem S. Tivantinib in hepatocellular carcinoma. Expert Opin Investig Drugs. 2013;22:141-147.

130. Rota Caremoli E, Labianca R. Tivantinib: critical review with a focus on hepatocellular carcinoma. Expert Opin Investig Drugs. 2014;23:1563-1574.

131. Santoro A, Rimassa L, Borbath I, Daniele B, Salvagni S, Van Laethem JL, et al. Tivantinib for second-line treatment of advanced hepatocellular carcinoma: a randomised, placebo-controlled phase 2 study. Lancet Oncol. 2013;14:55-63.

132. Yakes FM, Chen J, Tan J, Yamaguchi K, Shi Y, Yu P, et al. Cabozantinib (XL184), a novel MET and VEGFR2 inhibitor, simultaneously suppresses metastasis, angiogenesis, and tumor growth. Mol Cancer Ther. 2011;10:2298-2308

133. Siegel AB, Cohen El, Ocean A, Lehrer D, Goldenberg A, Knox Jل J et al. Phase II trial evaluating the clinical and biologic effects of bevacizumab in unresectable hepatocellular carcinoma. J Clin Oncol. 2008;26:2992-2998.

134. Boige V, Malka D, Bourredjem A, Dromain C, Baey C, Jacques N, et al. Efficacy, safety, and biomarkers of single-agent bevacizumab therapy in patients with advanced hepatocellular carcinoma. Oncologist. 2012;17:1063-1072.

135. Zhu AX, Park JO, Ryoo BY, Yen CJ, Poon R, Pastorelli D, et al. REACH trial investigators. Ramucirumab versus placebo as second-line treatment in patients with advanced hepatocellular carcinoma following first-line therapy with sorafenib (REACH): a randomised, double-blind, multicentre, phase 3 trial. Lancet Oncol. 2015;16:859-870.

136. Patrikidou A, Sinapi I, Regnault H, Fayard F, Bouattour M, Fartoux L, et al. Gemcitabine and oxaliplatin chemotherapy for advanced hepatocellular carcinoma after failure of anti-angiogenic therapies. Invest New Drugs. 2014;32:1028-1035.

137. Sangro B, Gomez-Martin C, de la Mata M, Iñarrairaegui M, Garralda E, Barrera P, et al. A clinical trial of CTLA-4 blockade with tremelimumab in patients with hepatocellular carcinoma and chronic hepatitis C. J Hepatol. 2013;59:81-88.

138. Heo J, Reid T, Ruo L, Breitbach CJ, Rose S, Bloomston M, et al. Randomized dose-finding clinical trial of oncolytic immunotherapeutic vaccinia JX-594 in liver cancer. Nat Med. 2013;19:329-336.

139. Segler A, Tsimberidou AM. Lenalidomide in solid tumors. Cancer Chemother Pharmacol. 2012;69:1393-1406.

140. Faivre SJ, Santoro A, Kelley RK, Merle P, Gane E, Douillard J-Y, et al. A phase 2 study of a novel transforming growth factor-beta (TGF-\{beta\} 1) receptor I kinase inhibitor, LY2157299 monohydrate (LY), in patients with advanced hepatocellular carcinoma (HCC). In: ASCO Annual Meeting Proceedings. 2014;2014. p. LBA173.

141. Chan SL, Wong AM, Lee K, Wong N, Chan AK. Personalized therapy for hepatocellular carcinoma: where are we now?. Cancer Treat Rev. 2016:45:77-86.

142. Ahmed M, Brace CL, Lee FT, Goldberg SN. Principles of and advances in percutaneous ablation. Radiology. 2011;258:351-369.
143. Chen K, Chen G, Wang H, Li H, Xiao J, Duan X, et al. Increased survival in hepatocellular carcinoma with iodine-125 implantation plus radiofrequency ablation: a prospective randomized controlled trial. J Hepatol. 2014:61:1304-1311.

144. Ahlers O, Hildebrandt B, Dieing A, Deja M, Böhnke T, Wust P, et al. Stress induced changes in lymphocyte subpopulations and associated cytokines during whole body hyperthermia of 41.8-42.2 degrees C. Eur J Appl Physiol. 2005;95:298-306.

145. Cui J, Wang N, Zhao H, Jin H, Wang G, Niu C, et al. Combination of radiofrequency ablation and sequential cellular immunotherapy improves progression-free survival for patients with hepatocellular carcinoma. Int J Cancer. 2014;134:342-351.

146. Wang XP, Xu M, Gao HF, Zhao JF, Xu KC. Intraperitoneal perfusion of cytokine-induced killer cells with local hyperthermia for advanced hepatocellular carcinoma. World J Gastroenterol. 2013;19:2956-2962.

147. Dong Y, Wu G. Analysis of short and long term therapeutic effects of radiofrequency hyperthermia combined with conformal radiotherapy in hepatocellular carcinoma. J buon. 2016;21:407-411.

148. Li Z, Zhang K, Lin SM, Mi DH, Cao N, Wen ZZ, et al. Radiofrequency ablation combined with percutaneous ethanol injection for hepatocellular carcinoma: a systematic review and meta-analysis. Int J Hyperthermia. 2016:1-10.

149. lezzi R, Pompili M, La Torre MF, Campanale MC, Montagna M, Saviano A et al. HepatoCATT study group for the multidisciplinary management of HCC. Radiofrequency ablation plus drug-eluting beads transcatheter arterial chemoembolization for the treatment of single large hepatocellular carcinoma. Dig Liver Dis. 2015:47:242-248.

150. Hoffmann R, Rempp H, Syha R, Ketelsen D, Pereira PL, Claussen CD, et al. Transarterial chemoembolization using drug eluting beads and subsequent percutaneous MR-guided radiofrequency ablation in the therapy of intermediate sized hepatocellular carcinoma. Eur J Radiol. 2014;83:1793-1798

151. Huang ZM, Li W, Li S, Gao F, Zhou QM, Wu FM, et al. Cytokine-induced killer cells in combination with transcatheter arterial chemoembolization and radiofrequency ablation for hepatocellular carcinoma patients. J Immunother. 2013:36:287-293.

152. Cui L, Liu XX, Jiang Y, Wu XJ, Liu JJ, Zhou XR, et al. Comparative study on transcatheter arterial chemoembolization, portal vein embolization and high intensity focused ultrasound sequential therapy for patients. Asian Pac J Cancer Prev. 2012;13:6257-6261.

153. Bush DA, Smith JC, Slater JD, Volk ML, Reeves ME, Cheng J, et al. Randomized clinical trial comparing proton beam radiation therapy with transarterial chemoembolization for hepatocellular carcinoma: results of an interim analysis. International J Radiat Oncol Biol Phys. 2016;95:477-482.

154. Lobo L, Yakoub D, Picado O, Ripat C, Pendola F, Sharma R, et al. Unresectable hepatocellular carcinoma: radioembolization versus chemoembolization: a systematic review and meta-analysis. Cardiovasc Intervent Radiol. 2016;39:1580-1588.

155. Zhang Y, Li Y, Ji H, Zhao X, Lu H. Transarterial Y 90 radioembolization versus chemoembolization for patients with hepatocellular carcinoma: a metaanalysis. Biosci Trends. 2015;9:289-298.

156. Ma J, Wang JH. ${ }^{131}$-Labeled-metuximab plus transarterial chemoembolization in combination therapy for unresectable hepatocellular carcinoma: results from a multicenter phase IV clinical study. Asian Pac J Cancer Prev. 2015;16:7441-7447.

157. Wu L, Yang YF, Ge NJ, Shen SQ, Liang J, Wang Y, et al. Hepatic artery injection of ${ }^{131}$ |-labelled metuximab combined with chemoembolization for intermediate hepatocellular carcinoma: a prospective nonrandomized study. Eur J Nucl Med Mol Imaging. 2012;39:1306-1315.

158. Peng S, Yang QX, Zhang T, Lu MJ, Yang G, Liu ZY, et al. Lobaplatin-TACE combined with radioactive ${ }^{125}$ s seed implantation for treatment of primary hepatocellular carcinoma. Asian Pac J Cancer Prev. 2014;15:5155-5160.

159. Jacob R, Turley F, Redden DT, Saddekni S, Aal AK, Keene K, et al. Adjuvant stereotactic body radiotherapy following transarterial chemoembolization in patients with non-resectable hepatocellular carcinoma tumours of $\geq 3 \mathrm{~cm}$. HPB (Oxford). 2015;17:140-149.

160. Ni S, Liu L, Shu Y. Sequential transcatheter arterial chemoembolization, three-dimensional conformal radiotherapy, and high-intensity focused ultrasound treatment for unresectable hepatocellular carcinoma patients. J Biomed Res. 2012;26:260-267.

161. Lin XJ, Li QJ, Lao XM, Yang H, Li SP. Transarterial injection of recombinant human type-5 adenovirus $\mathrm{H} 101$ in combination with transarterial chemoembolization (TACE) improves overall and progressive-free survival in unresectable hepatocellular carcinoma (HCC). BMC Cancer. 2015:15. 
162. Song DS, Song MJ, Bae SH, Chung WJ, Jang JY, Kim YS, et al. A comparative study between sorafenib and hepatic arterial infusion chemotherapy for advanced hepatocellular carcinoma with portal vein tumor thrombosis. J Gastroenterol. 2015;50:445-454.

163. Kawaoka T, Aikata H, Hyogo H, Morio R, Morio K, Hatooka M, et al. Comparison of hepatic arterial infusion chemotherapy versus sorafenib monotherapy in patients with advanced hepatocellular carcinoma. J Dig Dis. 2015;16:505-512.

164. Cosgrove DP, Reyes DK, Pawlik TM, Feng AL, Kamel IR, Geschwind JF. Open-label single-arm phase II trial of sorafenib therapy with drug-eluting bead transarterial chemoembolization in patients with unresectable hepatocellular carcinoma: clinical results. Radiology. 2015:277:594-603.

165. Buijs M, Reyes DK, PawlikTM, Blackford AL, Salem R, Messersmith WA, et al. Phase 2 trial of concurrent bevacizumab and transhepatic arteria chemoembolization in patients with unresectable hepatocellular carcinoma. Cancer. 2013;119:1042-1049.

166. Chen J, Zhou C, Long Y, Yin X. Sunitinib combined with transarterial chemoembolization versus transarterial chemoembolization alone for advanced-stage hepatocellular carcinoma: a propensity score matching study. Tumour Biol. 2015;36:183-191.

167. Feng X, Xu R, Du X, Dou K, Qin X, Xu J, et al. Combination therapy with sorafenib and radiofrequency ablation for BCLC stage 0-B1 hepatocellular carcinoma: a multicenter retrospective cohort study. Am J Gastroenterol. 2014;109:1891-1899.
168. Kan X, Jing Y, Wan QY, Pan JC, Han M, Yang Y, et al. Sorafenib combined with percutaneous radiofrequency ablation for the treatment of mediumsized hepatocellular carcinoma. Eur Rev Med Pharmacol Sci. 2015;19: 247-255.

169. Nakazawa T, Hidaka H, Shibuya A, Okuwaki Y, Tanaka Y, Takada J, et al. Overall survival in response to sorafenib versus radiotherapy in unresectable hepatocellular carcinoma with major portal vein tumor thrombosis: propensity score analysis. BMC Gastroenterol. 2014;14

170. Yang Y, Lu Y, Wang C, Bai W, Qu J, Chen Y, et al. Cryotherapy is associated with improved clinical outcomes of sorafenib for the treatment of advanced hepatocellular carcinoma. Exp Ther Med. 2012;3:171-180.

171. Chow PK, Poon DY, Khin MW, Singh H, Han HS, Goh AS, et al. AsiaPacific hepatocellular carcinoma trials group. Multicenter phase II study of sequential radioembolization-sorafenib therapy for inoperable hepatocellular carcinoma. PLoS ONE. 2014;9:e90909.

172. Feng Q, Chi Y, Liu Y, Zhang L, Liu Q. Efficacy and safety of percutaneous radiofrequency ablation versus surgical resection for small hepatocellular carcinoma: a meta-analysis of 23 studies. J Cancer Res Clin Oncol. 2015;141:1-9.

173. Yi HM, Zhang W, Ai X, Li KY, Deng YB. Radiofrequency ablation versus surgical resection for the treatment of hepatocellular carcinoma conforming to the Milan criteria: systemic review and meta-analysis. Int J Clin Exp Med. 2014;7:3150-3163. 